\title{
Extracorporeal membrane oxygenation resuscitation in adult patients with refractory septic shock
}

\author{
Chun-Ta Huang, MD, ${ }^{\text {a,b }}$ Yi-Ju Tsai, $\mathrm{PhD},{ }^{\mathrm{c}} \mathrm{Pi}-\mathrm{Ru}$ Tsai, RN, ${ }^{\mathrm{d}}$ and Wen-Je Ko, MD, PhD ${ }^{\mathrm{a}, \mathrm{d}}$
}

Objectives: Experience with extracorporeal membrane oxygenation for adult patients with refractory septic shock remains limited. We aimed to study the clinical features and outcomes of this patient group in an extracorporeal membrane oxygenation referral center in Taiwan.

Methods: From January 2005 to December 2010, all adult patients in refractory septic shock and requiring venoarterial extracorporeal membrane oxygenation for circulatory support were included in the present study. The variables analyzed included patient demographics; comorbidities; smoking status; hemodynamic, ventilatory, and laboratory parameters just before extracorporeal membrane oxygenation support; clinical course; extracorporeal membrane oxygenation details; complications; microbiology results; and outcomes. The primary endpoint was survival to hospital discharge.

Results: A total of 52 patients, 39 men and 13 women, were included during a 6-year period. Their median age and body mass index was 56.8 years and $24.1 \mathrm{~kg} / \mathrm{m}^{2}$, respectively. Of the 52 patients, $39(75 \%)$ had failure of at least 3 organ systems and $21(40 \%)$ had developed cardiac arrest and received cardiopulmonary resuscitation at extracorporeal membrane oxygenation implantation. Of these 52 patients, $8(15 \%)$ survived to hospital discharge. The nonsurvivors were significantly older than the survivors (59.3 vs 43.8 years; $P=.009)$, and all 20 patients $(38 \%)$ aged 60 years or older died.

Conclusions: In our single-center experience with extracorporeal membrane oxygenation for adults with refractory septic shock, the outcomes of these patients remain unsatisfactory. From our findings, we suggest that if extracorporeal membrane oxygenation were to be used in this patient population, age 60 years or older might be a contraindication. Also, central extracorporeal membrane oxygenation could possibly be beneficial according to the favorable pediatric experience in published studies. (J Thorac Cardiovasc Surg 2013;146:1041-6)

Septic shock, the most severe form of sepsis, is a common disease process in critically ill patients. ${ }^{1}$ Despite advances in critical care and the availability of potent antimicrobial therapy, the mortality rate associated with septic shock remains high, largely owing to the progressively compromised organ perfusion and development of multiple organ failure. $^{2,3}$ For septic shock unresponsive to all other measures, the American College of Critical Care Medicine has suggested that extracorporeal membrane oxygenation (ECMO) is a viable therapy in neonates and children. ${ }^{4}$ However, although successful use of ECMO in adults with refractory septic shock has been reported in a few cases, ${ }^{5-8}$ the experience with ECMO in adults with septic shock remains limited.

Accordingly, we performed a retrospective cohort study of adult patients who had received ECMO for refractory

\footnotetext{
From the Departments of Traumatology, ${ }^{\mathrm{a}}$ Internal Medicine, ${ }^{\mathrm{b}}$ and Surgery, ${ }^{\mathrm{d}}$ National Taiwan University Hospital, Taipei, Taiwan; and School of Medicine, ${ }^{\mathrm{c}}$ Fu-Jen Catholic University College of Medicine, Taipei, Taiwan.

Disclosures: Authors have nothing to disclose with regard to commercial support.

Received for publication June 14, 2012; revisions received July 28, 2012; accepted for publication Aug 3, 2012; available ahead of print Sept 10, 2012.

Address for reprints: Wen-Je Ko, MD, PhD, Departments of Traumatology and

Surgery, National Taiwan University Hospital, No. 7, Chung-Shan South Rd,

Taipei 100, Taiwan (E-mail: kowj@ntu.edu.tw).

$0022-5223 / \$ 36.00$

Copyright (c) 2013 by The American Association for Thoracic Surgery

http://dx.doi.org/10.1016/j.jtcvs.2012.08.022
}

septic shock and aimed to describe the clinical features and survival of this patient group.

\section{METHODS}

\section{Study Population}

The present study was conducted at the National Taiwan University Hospital, a university-affiliated hospital with a 2200-bed capacity in Northern Taiwan. It delivers both primary and tertiary healthcare and also has an ECMO referral center. For quality assurance, a computerized case record form was established to prospectively collect the demographic, clinical features, and outcomes of patients undergoing ECMO. ${ }^{9}$ We searched the ECMO database for adult patients who required ECMO for refractory septic shock between January 2005 and December 2010. Patients were eligible for the present study if they were 18 years or older, had received venoarterial ECMO for circulatory collapse despite fluid resuscitation and inotropic therapy, had a clinical diagnosis of septic shock, and had a positive culture or serology result for potentially pathogenic microorganisms before ECMO implantation. Patients were excluded if they had received ECMO primarily for respiratory support. The institutional review board approved the present study and waived the need for informed consent.

\section{General Management of Septic Shock}

A severe sepsis management protocol has been implemented according to the Surviving Sepsis Campaign guidelines at our institution since $2005 .^{10}$ In brief, patients presenting to the intensive care unit with septic shock are initially treated with aggressive fluid challenge. If fluidrefractory shock persists, a vasoactive agent, such as dopamine or norepinephrine, is administered. Measurements of central venous pressure, central venous oxygen saturation, and serum lactate are performed early to 


\section{Abbreviation and Acronym \\ $\mathrm{ECMO}=$ extracorporeal membrane oxygenation}

guide fluid and inotropic therapy. Arginine vasopressin or epinephrine is given if a patient shows signs of ongoing shock or progressive organ dysfunction. Low-dose corticosteroid infusion and packed red blood cell transfusion are considered in the case of refractory shock.

\section{ECMO Setup}

Cannulation was performed by cardiovascular surgeons, who generally cannulated the femoral artery and vein. Only if it was difficult to obtain peripheral vascular access or left-sided decompression was required was central cannulation through a median sternotomy performed. The ECMO system consisted of a centrifugal blood pump (Bio-Pump BP-80; Medtronic, Minneapolis, Minn), a hollow-fiber membrane oxygenator (Affinity; Omnis AOT GmbH, Bad Oyenhausen, Germany) with an integral heat exchanger, and 2 thin-walled cannulae (Medtronic Inc, Anaheim, Calif), all of which were coated with a heparin-bonded Carmeda BioActive Surface (Carmeda AB, Upplands Väsby, Sweden). A distal reperfusion catheter was inserted to prevent distal limb ischemia, as clinically indicated. ${ }^{11}$ Anticoagulation was achieved with intravenous unfractionated heparin infusion to maintain the activated clotting time at 180 to $220 \mathrm{sec}-$ onds. The blood flow was usually started at a rate of 2 to $2.5 \mathrm{~L} / \mathrm{min}$ and then adjusted according to the patient's hemodynamic status.

\section{Data Collection}

The variables retrieved included patient demographics; comorbidities; smoking status; hemodynamic, ventilatory, and laboratory data just before ECMO support; clinical course; ECMO details; complications; microbiology results; and outcomes. The primary endpoint was survival to hospital discharge. Organ failure was defined using the International Sepsis Definitions Conference criteria. ${ }^{12}$ A major bleeding complication during ECMO support was defined as the transfusion of $2 \mathrm{U}$ or more of packed red blood cells, a decrease in hematocrit of $10 \%$ or more, or any bleeding requiring surgical intervention or directly resulting in death. Appropriate antibiotic therapy was defined as effectiveness against the culprit microorganisms of at least 1 of the empirically selected antibiotics on the day of the ECMO implantation. Antibiotic effectiveness was evaluated according to the culture results and known susceptibility of the microorganism to the antibiotics prescribed and by antimicrobial susceptibility testing.

\section{Statistical Analysis}

Data are presented as numbers and percentages or median and interquartile range. Continuous variables were analyzed using the Mann-Whitney $U$-test and categorical variables using the Fisher exact test. Survival curves were plotted using the Kaplan-Meier method and compared using the logrank test. All statistics were 2-tailed. Statistical analyses were performed using the SPSS statistical software, version 15.0 (SPSS Inc, Chicago, Ill).

\section{RESULTS}

A total of 52 patients (7.9\%), 39 men and 13 women, were recruited from a total of 659 ECMO runs during the 6-year study period. The median age and body mass index was 56.8 years (interquartile range, $42.7-63.6)$ and $24.1 \mathrm{~kg} / \mathrm{m}^{2}$ (interquartile range, 21.2-27.5), respectively (Table 1). Diabetes mellitus $(12 / 52 ; 23 \%)$, coronary artery disease $(6 / 52 ; 12 \%)$, and end-stage renal disease $(6 / 52 ; 12 \%)$ were the most common comorbid diseases. The median sequential organ failure assessment score was 16 (interquartile range, 13-18), and 39 patients (75\%) had failure of at least 3 organ systems. The patients received ECMO for a median duration of 15.0 hours (interquartile range, 6.1-29.3) after the onset of septic shock. All patients had been orotracheally intubated and administered on mechanical ventilation before ECMO support. The survivors (age, 43.8 years) were significantly younger than the nonsurvivors (age, 59.3 years), and all 20 patients ( $38 \%$ ) aged 60 years or older died.

The most common infection sites were the lung and abdomen, accounting for $69 \%$ of the infections, and 23 patients $(44 \%)$ had positive blood cultures (Table 2). The infections were bacterial in most $(88 \%)$ patients, and gram-negative bacteria were isolated from $60 \%$ of the patients. Klebsiella pneumoniae and Pseudomonas aeruginosa were the most frequently identified pathogens. Of the 52 patients, $43(83 \%)$ had received appropriate antimicrobial agents on the day ECMO was instituted.

The circulatory, ventilatory, and laboratory variables before ECMO support are listed in Table 3. None of 52 patients had a history of congestive heart failure or developed acute heart failure or coronary events; however, 11 patients ( $21 \% ; 1$ survivor and 10 nonsurvivors) had a decreased left ventricular ejection fraction of less than $50 \%$, as evaluated by echocardiography at ECMO implantation. The survivors tended to have a lower pre-ECMO arterial lactate level than the nonsurvivors.

Of the 52 patients, $21(40 \%)$ developed rapid and severe hemodynamic deterioration and cardiac arrest and received cardiopulmonary resuscitation before the decision to institute ECMO support. The median duration of cardiopulmonary resuscitation was 29.0 minutes (interquartile range, 23.0-35.5; Table 4). A total of 36 patients $(69 \%)$ required hemofiltration during ECMO. The median duration of ECMO was 43.3 hours (interquartile range, 10.2-157.5). The survivors (162.9 hours) received ECMO for a significantly longer period than the nonsurvivors (27.3 hours). With respect to ECMO cannulation, the cannulae were placed in the femoral vein and artery (femoral-femoral cannulation) in all but 2 patients; 1 received jugular-femoral cannulation and 1 femoral-carotid cannulation. No patients required left-sided decompression or underwent central cannulation.

Of the 52 patients, $12(23 \%)$ experienced mechanical problems during ECMO support, including 9 oxygenator failures, 4 occasions in which a cannula needed to be repositioned, and 1 episode of blood clots in the circuit. Of these 12 patients, 2 experienced 2 different mechanical problems. There were $4(7.7 \%)$ major bleeding complications; 2 patients developed bleeding from the cannulation sites and 2 developed gastrointestinal hemorrhage, all of whom were treated conservatively. No patients died of these complications. All patients underwent instrumentation with a right 
TABLE 1. Baseline patient characteristics

\begin{tabular}{lccc}
\hline \multicolumn{1}{c}{ Characteristic } & $\begin{array}{c}\text { Survivors } \\
(\mathbf{n}=\mathbf{8})\end{array}$ & $\begin{array}{c}\text { Nonsurvivors } \\
(\mathbf{n}=\mathbf{4 4})\end{array}$ & $\boldsymbol{P}$ value \\
\hline Age (y) & 43.8 & 59.3 & .009 \\
Age $\geq 60$ y & $0(0)$ & $20(45)$ & .017 \\
Male gender & $7(88)$ & $32(73)$ & .662 \\
BMI $\left(\mathrm{kg} / \mathrm{m}^{2}\right)$ & 25.7 & 24.1 & .417 \\
Current smoker & $0(0)$ & $12(27)$ & .174 \\
Comorbidities & $1(13)$ & $20(46)$ & .122 \\
$\quad$ Diabetes mellitus & $0(0)$ & $12(27)$ & .174 \\
$\quad$ Coronary artery disease & $0(0)$ & $6(14)$ & .573 \\
$\quad$ End-stage renal disease & $1(13)$ & $5(11)$ & .999 \\
$\quad$ Chronic obstructive & $0(0)$ & $2(5)$ & .999 \\
$\quad$ pulmonary disease & & & \\
$\quad$ Liver cirrhosis & $0(0)$ & $1(2)$ & .999 \\
SOFA score & 15 & 17 & .546 \\
Dysfunctional organs & 3.5 & 3.0 & .844 \\
Patients with $\geq 3$ dysfunction & $6(75)$ & $33(75)$ & .999 \\
$\quad$ organs & & & \\
Interval from shock to start & 20.8 & 15.0 & .630 \\
$\quad$ of ECMO (h) & & & \\
\hline Data presented as n (\%) or median. $B M I$, Body mass index; SOFA, sequential organ \\
failure assessment; $E C M O$, extracorporeal membrane oxygenation.
\end{tabular}

radial arterial line, and no significant maldistribution of oxygen was clinically observed.

The median duration of the intensive care unit and hospital stay was 90.1 hours (interquartile range, 28.3-314.7) and 114.1 hours (interquartile range, 52.3-404.7), respectively. Of the 52 patients, $8(15 \%)$ survived to hospital discharge. Of those who died, $28(64 \%)$ died of refractory circulatory collapse within 48 hours after initiation of ECMO (Figure 1). The survival analysis showed that patients younger than 60 years had significantly better survival than those 60 years old or older (log-rank, $P=.029)$. Three of the nonsurvivors survived to be taken off ECMO; however, later, 2 died of hospital-acquired pneumonia and 1 died of a perforated peptic ulcer in the intensive care unit.

\section{DISCUSSION}

The present study was dedicated to investigate how well ECMO performs as rescue therapy for refractory septic shock in adults. The main findings were that the survival of patients with refractory septic shock and receiving ECMO support remains unsatisfactory and that age was the only independent factor associated with mortality in our study population.

Sepsis was once regarded as a contraindication for ECMO because the artificial circuits could harbor microorganisms and cause severe uncontrolled infection. However, advances in ECMO management and circuit technology have broadened the indications for ECMO, and patients with sepsis are no longer excluded as candidates for ECMO. Most promisingly, a survival rate of up to $74 \%$ was observed in children receiving ECMO as circulatory
TABLE 2. Sites and causes of infections in patients with refractory septic shock

\begin{tabular}{|c|c|c|c|}
\hline Variable & $\begin{array}{l}\text { Survivors } \\
(\mathbf{n}=\mathbf{8})\end{array}$ & $\begin{array}{c}\text { Nonsurvivors } \\
(n=44)\end{array}$ & $P$ value \\
\hline Infection sites & & & .391 \\
\hline Lung & $6(75)$ & $19(43)$ & \\
\hline Abdomen & $1(13)$ & $10(23)$ & \\
\hline Urinary tract & $0(0)$ & $5(11)$ & \\
\hline Others* & $1(13)$ & $10(23)$ & \\
\hline Positive blood culture & $4(50)$ & $19(43)$ & 999 \\
\hline Microorganism types & & & .277 \\
\hline Gram-positive & $3(38)$ & $11(25)$ & \\
\hline Staphylococcus species & $3(38)$ & $4(9)$ & \\
\hline Streptococcus species & $0(0)$ & $4(9)$ & \\
\hline Enterococcus species & $0(0)$ & $2(5)$ & \\
\hline Other gram-positive bacteria & $0(0)$ & $1(2)$ & \\
\hline Gram-negative & $3(38)$ & $28(64)$ & \\
\hline Klebsiella pneumoniae & $0(0)$ & $8(18)$ & \\
\hline Pseudomonas aeruginosa & $0(0)$ & $8(18)$ & \\
\hline Enterobacter species & $1(13)$ & $3(7)$ & \\
\hline Acinetobacter baumannii & $1(13)$ & $2(5)$ & \\
\hline Escherichia coli & $0(0)$ & $2(5)$ & \\
\hline Citrobacter species & $1(13)$ & $1(2)$ & \\
\hline Other gram-negative bacteria & $0(0)$ & $4(9)$ & \\
\hline \multicolumn{4}{|l|}{ Fungal } \\
\hline Candida species & $2(25)$ & $3(7)$ & \\
\hline \multicolumn{4}{|l|}{ Other } \\
\hline Mycoplasma pneumoniae & $0(0)$ & $1(2)$ & \\
\hline Influenza type A & $0(0)$ & $1(2)$ & \\
\hline Appropriate antibiotic therapy & $6(75)$ & $37(84)$ & .615 \\
\hline
\end{tabular}

Data presented as $\mathrm{n}(\%)$. *Other sites of infections included blood, skin and soft tissue, bones, and cardiac system.

support for refractory septic shock. ${ }^{13,14}$ In the present study, we reported a large case series of the application of ECMO in adult patients with refractory septic shock and found a prognosis for adults distinct from that for children. Several factors could account for the favorable outcome for pediatric patients. First, septic shock has a variety of hemodynamic presentations. Left ventricular dysfunction with reduced cardiac output is commonly seen in infants and younger children; however, distributive shock, a hyperdynamic state with high cardiac output, usually manifests in older children and adults. ${ }^{15}$ Venoarterial ECMO is used primarily for cardiac or cardiopulmonary support and is intuitively more beneficial for patients with ventricular dysfunction than for those with profound vasodilation. Thus, the performance of ECMO is probably better in pediatric than adult septic shock. Second, a significant proportion of pediatric patients with refractory septic shock underwent ECMO by central cannulation. ${ }^{13,14}$ In contrast, all of our patients with refractory septic shock received peripheral ECMO cannulation. Central cannulation might be associated with increased survival in the pediatric population. Its theoretical benefits include the ability to achieve greater flow rates and 
TABLE 3. Clinical parameters before extracorporeal membrane oxygenation

\begin{tabular}{|c|c|c|c|}
\hline Variable & $\begin{array}{l}\text { Survivors } \\
\qquad(\mathbf{n}=\mathbf{8})\end{array}$ & $\begin{array}{l}\text { Nonsurvivors } \\
\quad(n=44)\end{array}$ & $\begin{array}{r}P \\
\text { valu }\end{array}$ \\
\hline \multicolumn{4}{|l|}{ Circulatory } \\
\hline Mean arterial pressure $(\mathrm{mm} \mathrm{Hg})$ & 57.0 & 55.5 & .424 \\
\hline Inotropic equivalent* $(\mathrm{mcg} / \mathrm{kg} / \mathrm{min})$ & 52.8 & 56.0 & .275 \\
\hline $\begin{array}{l}\text { Urine output in hour before } \\
\text { ECMO }(\mathrm{mL} / \mathrm{kg} / \mathrm{h})\end{array}$ & 0.07 & 0.02 & .493 \\
\hline $\begin{array}{l}\text { Left ventricular ejection } \\
\text { fraction }(\%)\end{array}$ & 56.5 & 55.5 & .657 \\
\hline \multicolumn{4}{|l|}{ Ventilatory } \\
\hline Peak airway pressure $\left(\mathrm{cm} \mathrm{H}_{2} \mathrm{O}\right)$ & 30 & 30 & .980 \\
\hline Mean airway pressure $\left(\mathrm{cm} \mathrm{H}_{2} \mathrm{O}\right)$ & 17 & 15 & .341 \\
\hline $\begin{array}{l}\text { Positive end-expiratory } \\
\text { pressure }\left(\mathrm{cm} \mathrm{H}_{2} \mathrm{O}\right)\end{array}$ & 11 & 8 & .150 \\
\hline $\mathrm{FIO}_{2}$ & 0.65 & 0.60 & .552 \\
\hline \multicolumn{4}{|l|}{ Laboratory } \\
\hline $\mathrm{pH}$ & 7.32 & 7.30 & .960 \\
\hline $\mathrm{PaO}_{2} / \mathrm{FIO}_{2}$ & 89 & 112 & .233 \\
\hline $\mathrm{PaCO}_{2}(\mathrm{~mm} \mathrm{Hg})$ & 37.6 & 38.1 & .704 \\
\hline Base excess (mmol/L) & -6.6 & -6.3 & .899 \\
\hline Arterial lactate $(\mathrm{mmol} / \mathrm{L})$ & 5.3 & 8.8 & .089 \\
\hline
\end{tabular}

Data presented as median. $\mathrm{ECMO}$, Extracorporeal membrane oxygenation; $\mathrm{FIO}_{2}$, fraction of inspired oxygen; $\mathrm{PaO}_{2}$, arterial oxygen tension; $\mathrm{PaCO}_{2}$, alveolar carbon dioxide tension. *Inotropic equivalent $=$ dopamine + dobutamine $+100 \times$ epinephrine + $100 \times$ norepinephrine $+100 \times$ isoproterenol $+15 \times$ milrinone.

potentially reverse shock and organ dysfunction earlier and placement of the arterial cannula in the ascending aorta, which possibly improves cerebral perfusion and decreases the risk of neurologic injury compared with peripheral cannulation. ${ }^{13,14}$ Although the present study did not demonstrate a favorable outcome in adult patients undergoing ECMO for refractory septic shock, our findings have several implications. First, at present, ECMO is not recommended for use in routine clinical practice to rescue adult patients with refractory septic shock. Second, if it is used to treat such patients, the use

TABLE 4. Variables during ECMO in patients with refractory septic shock

\begin{tabular}{lccc}
\hline \multicolumn{1}{c}{ Variable } & $\begin{array}{c}\text { Survivors } \\
(\mathbf{n}=\mathbf{8})\end{array}$ & $\begin{array}{c}\text { Nonsurvivors } \\
(\mathbf{n}=\mathbf{4 4})\end{array}$ & $\boldsymbol{P}$ value \\
\hline E-CPR & $2(25)$ & $19(43)$ & .449 \\
CPR duration (min) & 30 & 29 & .952 \\
Maximal recorded flow (L/min) & 2.6 & 2.7 & .929 \\
Hemofiltration & $5(63)$ & $31(71)$ & .689 \\
Complications & $4(50)$ & $10(23)$ & .189 \\
$\quad$ Mechanical* & $3(38)$ & $9(20)$ & .366 \\
Hemorrhage $\dagger$ & $2(25)$ & $2(5)$ & .107 \\
ECMO duration $(\mathrm{h})$ & 162.9 & 27.3 & .007 \\
\hline
\end{tabular}

Data presented as n (\%) or median. ECMO, Extracorporeal membrane oxygenation; $E-C P R, \mathrm{ECMO}$ with continuous cardiopulmonary resuscitation; $C P R$, cardiopulmonary resuscitation. *Mechanical complications included oxygenator failure, cannula repositioning, and clot in circuit. †Hemorrhage complications included gastrointestinal hemorrhage and cannulation site bleeding.

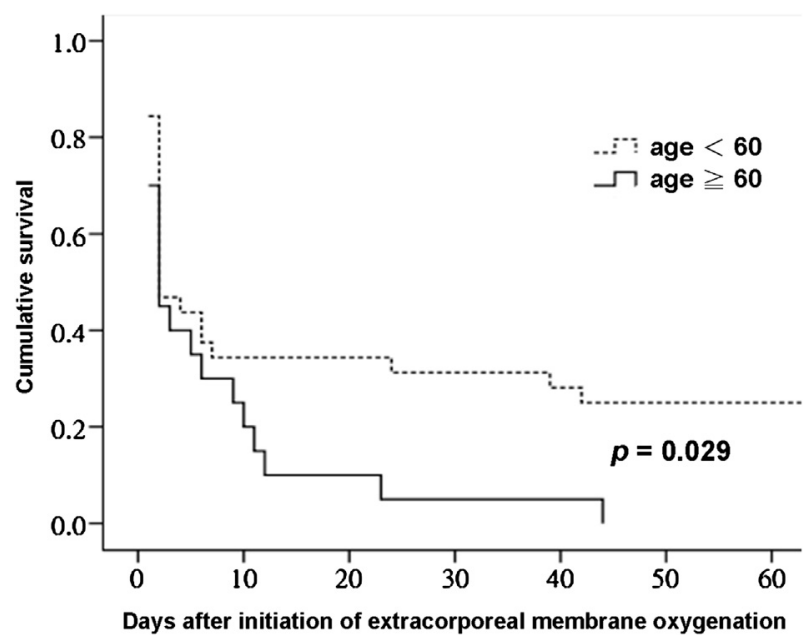

FIGURE 1. Survival curves for adult patients receiving extracorporeal membrane oxygenation for refractory septic shock. A significant proportion of patients died of refractory circulatory collapse within 2 days of initiation of extracorporeal membrane oxygenation support. Survival curves were plotted using the Kaplan-Meier method and compared using the log-rank test.

of central ECMO or other modifications should be seriously considered. Third, patient selection could be of paramount importance. For example, it is probably more appropriate to provide ECMO for patients with sepsisassociated myocardial dysfunction.

Most of our patients had preserved left ventricular systolic function at ECMO implantation and were intuitively considered to have distributive shock. This patient population might not traditionally be candidates for ECMO support. However, in the case of profound septic shock, it is difficult to determine whether the so-called preserved systolic function is sufficient to sustain the increased circulatory load that occurs in patients with thyrotoxicosis and high-output heart failure. ${ }^{16}$ Therefore, under such circumstances, we considered that it might still be beneficial to augment cardiac output using venoarterial ECMO to overcome the circulatory disaster.

One of the most important considerations for the institution of ECMO for refractory septic shock is whether the infection of a patient with refractory septic shock is under control. However, most of our patients experienced refractory septic shock or even cardiac arrest shortly after the onset of septic shock. At that time, it was difficult for clinicians to determine whether the infection could be successfully treated. Thus, other clinical characteristics should be sought to guide the application of ECMO in this regard. The present study found age was the only recognized prognostic variable in adults with refractory septic shock, and no patient aged 60 years or older survived to hospital discharge. This is in line with previous case reports ${ }^{5-8}$ that demonstrated successful rescue of refractory septic shock by ECMO in patients aged 18 to 46 years. Age is an 
unchangeable characteristic and predicts the outcome of various diseases. ${ }^{17-19}$ Many physiologic and immunologic functions in the human body are dynamically changing during the aging process, and these might not be easily measured in the clinical context. Accordingly, from our experience, we suggest that ECMO resuscitation might be contraindicated for patients aged 60 years or older who develop refractory septic shock.

The distribution of causative microorganisms and infection sites in our study was consistent with previous reports. ${ }^{20-22}$ Aerobic gram-negative bacteria were more common than aerobic gram-positive bacteria, and the lung, abdomen, and urinary tract accounted for most cases. In keeping with the published data, ${ }^{20}$ neither the infection site nor the causative microorganism was associated with mortality in the patients with septic shock requiring ECMO support. Several studies and meta-analyses have shown the favorable effect of early appropriate antimicrobial therapy in patients with severe sepsis and septic shock..$^{20,23,24}$ However, appropriate antibiotic therapy did not appear to confer a survival advantage in our patients. We speculate that an overwhelmingly uncontrolled inflammatory response plays a dominant role in these extremely critically ill patients, overriding the benefits of appropriate antibiotic therapy and leading to multiple organ dysfunction and, eventually, death. ${ }^{25}$

One might be wondering whether the patients in our study could have survived refractory septic shock without the use of ECMO. We believe this would not have been the case because, despite rescue by ECMO, the outcomes of the patients remained ominous. Moreover, all patients had profound shock and multiple organ dysfunction while receiving high-dose inotropic therapy. Two fifths of the patients had experienced cardiac arrest before receiving ECMO and this might partly explain the observed poor prognosis for our septic patients. Although it would be best to conduct a randomized trial to provide convincing evidence to answer the question, such a trial of a life-support technique in an acute fatal illness presents ethical problems, especially when the endpoint is death. Thus, our study has presented a large case series and might provide the strongest evidence to date in this regard.

The present study had some limitations that need to be addressed. This study presented a single-institution experience with the application of ECMO in adult patients with refractory septic shock. Undoubtedly, the study setting limited the strength and generalizability of the results. Nevertheless, our report provides the largest case series detailing the use of ECMO in such circumstances. With more widespread application of ECMO in the near future, it would be wise to perform a multicenter study of the population of interest to improve our understanding. Furthermore, the possibility of selection bias and low statistical power owing to the relatively small number of cases included in the analysis could not be excluded, and we might have failed to identify possible associated risk factors for mortality.

\section{CONCLUSIONS}

The outcome for ECMO resuscitation of adult patients with septic shock unresponsive to aggressive medical therapy remains poor. At present, it should not be regarded as a rescue modality for these patients. Furthermore, if ECMO is to be used for adult patients with refractory septic shock, some points merit consideration. First, patient age of 60 years or older might be a contraindication. Second, these patients might require central ECMO rather than peripheral venoarterial ECMO according to the published pediatric experience. Finally, the characteristics, clinical course, and outcomes of these patients should be systematically monitored to help us understand this issue more deeply.

\section{References}

1. Ruokonen E, Takala J, Kari A, Alhava E. Septic shock and multiple organ failure Crit Care Med. 1991;19:1146-51.

2. Friedman G, Silva E, Vincent JL. Has the mortality of septic shock changed with time. Crit Care Med. 1998;26:2078-86.

3. Russell JA, Singer J, Bernard GR, Wheeler A, Fulkerson W, Hudson L, et al Changing pattern of organ dysfunction in early human sepsis is related to mortality. Crit Care Med. 2000;28:3405-11.

4. Brierley J, Carcillo JA, Choong K, Cornell T, Decaen A, Deymann A, et al. Clinical practice parameters for hemodynamic support of pediatric and neonatal septic shock: 2007 update from the American College of Critical Care Medicine Crit Care Med. 2009;37:666-88.

5. MacLaren G, Pellegrino V, Butt W, Preovolos A, Salamonsen R. Successful use of ECMO in adults with life-threatening infections. Anaesth Intensive Care. 2004;32:707-10

6. Vohra HA, Adamson L, Weeden DF, Haw MP. Use of extracorporeal membrane oxygenation in the management of septic shock with severe cardiac dysfunction after Ravitch procedure. Ann Thorac Surg. 2009;87:e4-5.

7. Firstenberg MS, Abel E, Blais D, Louis LB, Steinberg S, Sai-Sudhakar C, et al. The use of extracorporeal membrane oxygenation in severe necrotizing soft tissue infections complicated by septic shock. Am Surg. 2010;76:1287-9.

8. MacLaren G, Cove M, Kofidis T. Central extracorporeal membrane oxygenation for septic shock in an adult with H1N1 influenza. Ann Thorac Surg. 2010;90:e34-5

9. Sun HY, Ko WJ, Tsai PR, Sun CC, Chang YY, Lee CW, et al. Infections occurring during extracorporeal membrane oxygenation use in adult patients. $J$ Thorac Cardiovasc Surg. 2010;140:1125-32.

10. Dellinger RP, Carlet JM, Masur H, Gerlach H, Calandra T, Cohen J, et al. Surviving sepsis campaign guidelines for management of severe sepsis and septic shock. Crit Care Med. 2004;32:858-73.

11. Huang SC, Yu HY, Ko WJ, Chen YS. Pressure criterion for placement of dista perfusion catheter to prevent limb ischemia during adult extracorporeal life support. J Thorac Cardiovasc Surg. 2004;128:776-7.

12. Levy MM, Fink MP, Marshall JC, Abraham E, Angus D, Cook D, et al. 2001 SCCM/ESICM/ACCP/ATS/SIS International Sepsis Definitions Conference. Crit Care Med. 2004;31:1250-6.

13. MacLaren G, Butt W, Best D, Donath S, Taylor A. Extracorporeal membrane oxygenation for refractory septic shock in children: one institution's experience. $P e$ diatr Crit Care Med. 2007;8:447-51.

14. MacLaren G, Butt W, Best D, Donath S. Central extracorporeal membrane oxygenation for refractory pediatric septic shock. Pediatr Crit Care Med. 2011;12: 133-6.

15. Maclaren G, Butt W. Extracorporeal membrane oxygenation and sepsis. Crit Care Resusc. 2007;9:76-80.

16. Klein I, Ojamaa K. Thyroid hormone and the cardiovascular system. N Engl J Med. 2001;344:501-9.

17. Na II, Choe du H, Kim CH, Koh JS, Ryoo BY, Lee JC, et al. Age at diagnosis predicts outcomes in gefitinib-treated female patients with non-small-cell lung cancer. Lung Cancer. 2010;68:295-8. 
18. Jarvinen O, Huhtala H, Laurikka J, Tarkka MR. Higher age predicts adverse outcome and readmission after coronary artery bypass grafting. World J Surg. 2003; 27:1317-22.

19. Sun BC, Hoffman JR, Mangione CM, Mower WR. Older age predicts short-term, serious events after syncope. J Am Geriatr Soc. 2007;55:907-12.

20. Zahar JR, Timsit JF, Garrouste-Orgeas M, Français A, Vesin A, DescorpsDeclere A, et al. Outcomes in severe sepsis and patients with septic shock: pathogen species and infection sites are not associated with mortality. Crit Care Med. 2011;39:1886-95.

21. Kumar A, Ellis P, Arabi Y, Roberts D, Light B, Parrillo JE, et al. Initiation of inappropriate antimicrobial therapy results in a fivefold reduction of survival in human septic shock. Chest. 2009;136:1237-48.
22. Opal SM, Garber GE, LaRosa SP, Maki DG, Freebairn RC, Kinasewitz GT, et al. Systemic host responses in severe sepsis analyzed by causative microorganism and treatment effects of drotrecogin alfa (activated). Clin Infect Dis. 2003;37:50-8.

23. Garnacho-Montero J, Garcia-Garmendia JL, Barrero-Almodovar A, JimenezJimenez FJ, Perez-Paredes C, Ortiz-Leyba C. Impact of adequate empirical antibiotic therapy on the outcome of patients admitted to the intensive care unit with sepsis. Crit Care Med. 2003;31:2742-51.

24. Paul M, Shani V, Muchtar E, Kariv G, Robenshtok E, Leibovici L. Systematic review and meta-analysis of the efficacy of appropriate empiric antibiotic therapy for sepsis. Antimicrob Agents Chemother. 2010;54:4851-63.

25. Hotchkiss RS, Karl IE. The pathophysiology and treatment of sepsis. $N$ Engl J Med. 2003;348:138-50. 